\title{
How does obesity influences anatomopathologic features in radical prostatectomy specimen? Importance of body fat mass distribution
}

\author{
Morán E, Budía A, Martínez-Sarmiento M, Broseta E, Cámara $\mathrm{R}^{*}$, Boronat F \\ Urology Department, Endocrinology Department, Universitary and Polytechnic Hospital La Fe, Valencia, Spain
}

\begin{abstract}
Introduction: Contradictory conclusions can be found about the association between obesity and anatomopathologic features in prostate cancer specimen.

Objective: the aim of our study was to evaluate the association between body fat mass distribution measured by bioelectrical impedanciometry (BEI) with Gleason grade, positive surgical margins and tumour burden.

Material and Methods: A total of 61 patients were included in a prospective study who underwent radical prostatectomy. Body fat mass(BFM) distribution was obtained by BEI. Specialized uropathologist defined Gleason Grade, tumour burden in percentage and the presence of positive surgical margins. Gleason Grade was categorized in five groups. For univariate analysis T-Student and ANOVA test were done. For multivariate analysis, bivariant logistic regression was performed. Correlation analysis was performed by using the logistic linear regression.
\end{abstract}

Results: BMI and internal BFM were associated with high Gleason grade Internal body fat mass showed a correlation with tumour burden so for each kilogram of internal body fat mass, tumour burden increases a $0,18 \%$. Only age and height showed an association with positive surgical margins ( $\mathrm{p}=0,02 / \mathrm{p}=0,01 \mathrm{respectively)}$.

Conclusions: BMI and internal BFM demonstrated an association with higher Gleason grade in radical prostatectomy. A weak positive correlation was showed between internal body fat mass and tumour burden. We found no association with positive surgical margins.

\section{Introduction}

Prostate cancer (PC) is currently the most frequent non-cutaneous solid neoplasia in men and the second cause of death by cancer [1]. The pathological features of radical prostatectomy specimen that define the loco-regional aggressiveness of this neoplasia are Gleason grade, tumour burden and the presence of positive surgical margins. These items may influence in the progression free survival, cancer specific survival or overall survival. For this reason, it may be important to study factors that may be related to such adverse pathological patterns.

Some authors have defended the influence of obesity in the diagnosis of prostate cancer [2]. Unfortunately, the conclusions of current literature are, nowadays, still controversial. However, it has been recently evidenced that this central fat distribution is associated with metabolic syndrome and insulin resistance [3]. All of them, well known factors that can be in association with high grade prostate cancer.

The fact that the majority of the papers in this issue use BMI as body fat distribution measure could justify unalike conclusions since it has been shown that BMI is not an accurate body fat distribution measure. Bioelectrical impedanciometry (BEI) is, on the other hand, a safe, not expensive, fast, accessible and highly reproducible technique for this purpose [4].

The aim of our study was to evaluate the relationship between BEI data and aggressiveness features on the specimen of radical prostatectomy.

\section{Material and Methods}

An observational prospective single-center study was design including a total of 61 patient's candidates to radical prostatectomy conducted in the period from January 2013 to December 2014. Authors confirm that the study was reviewed and approved by the Ethics Committee (register number 0153) and conducted according to the Declaration of Helsinki.

We excluded patients with salvage radical prostatectomy after any kind of previous prostate cancer treatment (radiotherapy, brachitherapy or focal treatment).

\section{Body fat distribution measurement}

All patients were submitted to the Endocrinology Department to perform a fat mass distribution study. Bioelectrical impedanciometry was perform in all patients the day before the diagnostic prostate biopsy wich was done with a mean time of 2,7 months before prostate cancer

Correspondence to: Eduardo Morán Pascual, Urology Department, Universitary and Polytechnic Hospital La Fe, Valencia, Spain, Tel: 0034 647236089, E-mail: edumoranpascual@gmail.com

Key words: prostate cancer, obesity, gleason score, bioelectrical impedance, tumor burden

Received: October 03, 2017; Accepted: October 24, 2017; Published: October 26, 2017 
treatment. All patients were advice to report changes in medications or sudden changes in weight before biopsy or prostate cancer treatment. Abdominal Fat analyser AB-140 TANITA ${ }^{\circledR}$ GMON software was used and guidelines of the International Society for the Advance of the Kineanthropometry (ISAK) [5] were followed. BMI was categorized in normal weight $(\mathrm{BMI}<25)$, overweight $(25-30)$ and obesity $(>30)[6]$.

Afterwards, to perform BEI, patient was placed in a supine position with both hands over the chest. Abdominal Fat Analyser AB-140 TANITA $^{\circledR}$ was centred over the belly and detection electrodes were placed around it. Then, $\%$ of central body fat mass(BFM), \% total BFM, and internal BFM were achieved.

\section{Radical Prostatectomy}

All patients underwent laparoscopic radical prostatectomy. Gleason grade in radical prostatectomy specimen was categorized in five groups according to last evidence, Group 1 (Gleason 6), Group 2 (Gleason $73+4$ ), Group 3 (Gleason $74+3$ ), Group 4 (Gleason 8), Group 5 (Gleason 9-10) [7].

\section{Statistical analysis}

A sample size of 60 was estimated to provide $80 \%$ power to detect a $20 \%$ difference in between group changes in \% of body fat mass with a 2-sided alpha of 0.05 . The statistical significance of the differences between groups was compared via T-Student or ANOVA test. Binary logistic regression was used to examine the independent effect of each variable for Gleason grade or positive surgical margins. Correlation analysis was performed by using the logistic linear regression.

Authors confirm that the study was reviewed and approved by the Hospital La Fe Ethics Committee (register number 0153) and it was conducted according to the Declaration of Helsinki.

\section{Results}

The clinical characteristics of the patients are shown in table 1.

In our sample 4 patients $(6,6 \%)$ had normal weight, 34 (55,7\%) were overweight patients and $23(37,7 \%)$ were obese. Regarding Gleason grade we found this distribution: Group 1 (16 patients 26,2\%), Group 2 (23 patients $37,7 \%$ ), Group 3 (12 patients 19,6\%), Group 4 (7 patients $11,5 \%)$, Group 5 (3 patients 5,0\%). Differences in anthropometric measures are shown in table 2. Results from the ANOVA test were that only BMI and Internal BFM showed differences inter-groups ( $p=0,016$, $\mathrm{p}=0,001$ respectively). In fact, group 1 had statistically lower mean BMI than groups $3(\mathrm{p}=0,01) 4(\mathrm{p}=0,01)$ and $5(\mathrm{p}=0,05$, trend $)$ and also higher internal BFM than groups $4(0,02)$ and $5(\mathrm{p}=0,001)$

The analysis of tumour burden revealed a mean tumour burden of $11,87 \%(3,23-90,1)$.

Central body fat mass showed a weak but statistically significant positive correlation with tumour burden ( $\mathrm{r}$ Pearson $=0,29 \mathrm{p}=0,02$ ). Similarly, internal body fat mass showed a positive statistically significant correlation with tumour burden ( $\mathrm{r}$ Pearson $0,30 \mathrm{p}=0,02$ ) (Figure 1 and 2).

Table 1. Clinical and anthropometric description of patients with Radical prostatectomy.

\begin{tabular}{|c|c|}
\hline Variable & Mean (CI95) \\
\hline Age (years) & $63,48(47-74)$ \\
\hline BMI $\left(\mathrm{Kg} / \mathrm{m}^{2}\right)$ & $28,75(24,51-31,12)$ \\
\hline Central BFM $(\%)$ & $34,48(31,42-36,24)$ \\
\hline Total BFM $(\mathrm{Kg})$ & $22,05(18,21-23,95)$ \\
\hline Internal BFM $(\%)$ & $19,24(16,77-21,26)$ \\
\hline
\end{tabular}

According to these results we perform a simple linear regression to analyze the correlation between tumour burden and internal body fat mass (Table 3) concluding that for each kilogram of internal body fat mass, tumour burden increases a $0,183 \%$.

Our results revealed an $18,03 \%$ of positive surgical margins. Univariate analysis is shown in table 4 . Younger and taller patients had more percentage of positive surgical margins. Nevertheless, none of these variables has an independent risk factor in multivariate analysis.

\section{Discussion}

Fortunately, mortality derived from prostate cancer has decrease, mainly because of an earlier diagnosis and better treatment. Follow up is also very important and it is of paramount importance an accurate risk classification. A better understanding of risk factors, as obesity, and how they interact with disease behaviour could help urologist to improve our results in treating this neoplasy.

In our study, the analysis of the anthropometric data showed that BMI and internal body fat mass were associated with the presence of higher Gleason grade.

Similar results can be found in the literature. Freedland, et al. [8] observed that the percentage of patients with Gleason 8-10 doubled when comparing patients with normal weight (5\%) with obese patients (10\%).

Again, years later, Freedland, et al. [9] published new results of a retrospective study with more than 2,000 patients analyzed. In addition to Gleason grade, other parameters such as the percentage of tumour volume, tumour size and the presence of positive margins were studied. In that work, authors found higher Gleason grade tumours (defined in this study as those with greater than 7 Gleason grade) in obese patients.

Our results are consistent with the conclusions of the group of Amling, et al. [10] who observed that obese patients had statistically significantly higher degrees of Gleason that those non-obese. Unfortunately, none of the studies in the literature used the BEI. Thus, it seems unanimous that there is an association between BMI and Gleason grade in radical prostatectomy specimen. However, ours is the only work that employs the BEI and is so far the only reference that has studied the distribution of body fat distribution related to Gleason grade.

In our series, we have found a weak positive correlation, between internal body fat mass and the percentage of central fat mass with tumour burden ( $r=0.30$ and 0.29 respectively). In fact, per each kilogram of fat gained in internal organs, tumour burden increases $0.18 \%$ according to our results.

In the available literature, only a work of Tomaszewski, et al. [11] analyzed the percentage of existing tumour tissue in the specimen of radical prostatectomy and its relationship with BMI. No association between BMI and percentage of tumour burden was evident in this retrospective study with more than 2,500 patients $(\mathrm{p}=0,67)$. The employ of BEI and its usefulness in the definition of the distribution of body fat mass can justify possible differences with our study. In fact, in our series, neither BMI presented an association with the tumour burden but central body fat mass did so. This means that the data derived from the BEI may provide more information than the collected only by BMI.

The third of the parameters analyzed in the pathological report was the presence of positive surgical margins. Freedland, et al. [8] studied if there was any association between BMI and a higher rate of 
Table 2. Descriptive and comparative analysis of categorized Gleason grade in radical prostatectomy specimen.

\begin{tabular}{|c|c|c|c|c|}
\hline Variable & $\begin{array}{c}\text { Grade 1 } \\
\text { Mean (CI95) }\end{array}$ & $\begin{array}{c}\text { Grade 2 } \\
\text { Mean (CI95) }\end{array}$ & $\begin{array}{c}\text { Grade 3 } \\
\text { Mean (CI95)3 }\end{array}$ & $\begin{array}{c}\text { Grade 4 } \\
\text { Mean (CI95) }\end{array}$ \\
\hline $\mathrm{n}$ & 16 & 23 & 12 & 7 \\
\hline BMI $\left(\mathrm{Kg} / \mathrm{m}^{2}\right)$ & $26,56(24,51-27,41)$ & $27,94(26,33-29,54)$ & $30,84(28,50-33,18)$ & $29,36(26,51-32,21)$ \\
\hline Central BFM (\%) & $19,42(16,24-22,60)$ & $17,80(15,52-20,09)$ & $21,35(17,28-25,42)$ & $15,14(12,52-17,75)$ \\
\hline Total BFM (Kg) & $20,65(15,70-25,60)$ & $21,29(17,06-25,52)$ & $25,93(19,87-31,98)$ & $20,38(14,73-26,03)$ \\
\hline Internal BFM (\%) & $19,42(16,24-22,60)$ & $17,80(15,52-20,09)$ & $21,35(17,28-25,42)$ & $25,16-34,85)$ \\
\hline
\end{tabular}

Table 3. Simple linear regression analysis between tumour burden and internal body fat mass.

\begin{tabular}{|c|c|c|c|c|c|c|c|c|c|}
\hline \multirow{3}{*}{$\begin{array}{c}\text { Model } \\
\text { (Constant) }\end{array}$} & \multirow{2}{*}{\multicolumn{2}{|c|}{ Non-standard coeff. B St. Desv }} & \multirow{3}{*}{$\begin{array}{c}\text { Standard coeff. } \\
\text { Beta }\end{array}$} & \multirow{3}{*}{$\begin{array}{c}\mathbf{t} \\
13,9 \\
\end{array}$} & \multirow{3}{*}{$\begin{array}{l}\text { Sig } \\
00\end{array}$} & \multicolumn{2}{|c|}{ CI95 B } & \multirow{2}{*}{\multicolumn{2}{|c|}{$\begin{array}{c}\text { Colinearity statistics Toleranc. } \\
\text { VIF }\end{array}$}} \\
\hline & & & & & & \multirow{2}{*}{$\begin{array}{l}\text { Min. } \\
14,54\end{array}$} & \multirow{2}{*}{$\begin{array}{l}\text { Max. } \\
19,41\end{array}$} & & \\
\hline & 16,97 & 1,216 & & & & & & & \\
\hline Burden &, 183 &, 076 & 300 & 2,39 & 02 &, 030 &, 336 & 1,000 & 1,00 \\
\hline
\end{tabular}

Table 4. Univariate analysis of positive surgical margins.

\begin{tabular}{|c|c|c|c|}
\hline Variable & $\begin{array}{l}\text { Negative SM } \\
\text { Mean (CI95) }\end{array}$ & $\begin{array}{c}\text { Positive SM } \\
\text { Mean (CI95) }\end{array}$ \\
\hline $\mathrm{n}$ & 50 & 11 \\
\hline Age (years) & $64,32(62,38-66,25)$ & $58,60(52,23-64,97)$ \\
\hline Height (cm) & $163,10(157,08-169,12)$ & $169,26(160,80-171,72)$ \\
\hline BMI $\left(\mathrm{Kg} / \mathrm{m}^{2}\right)$ & $28,47(27,43-29,52)$ & $28,92(27,22-30,62)$ \\
\hline Central B. fat mass (\%) & $33,69(31,54-35,85)$ & $33,92(30,64-37,19)$ \\
\hline Total B. fat mass (Kg) & $22,81(19,88-25,74)$ & $18,32(13,98-22,65)$ \\
\hline Internal B. fat mass (\%) & $18,90(17,05-20,75)$ & 0,40 \\
\hline
\end{tabular}

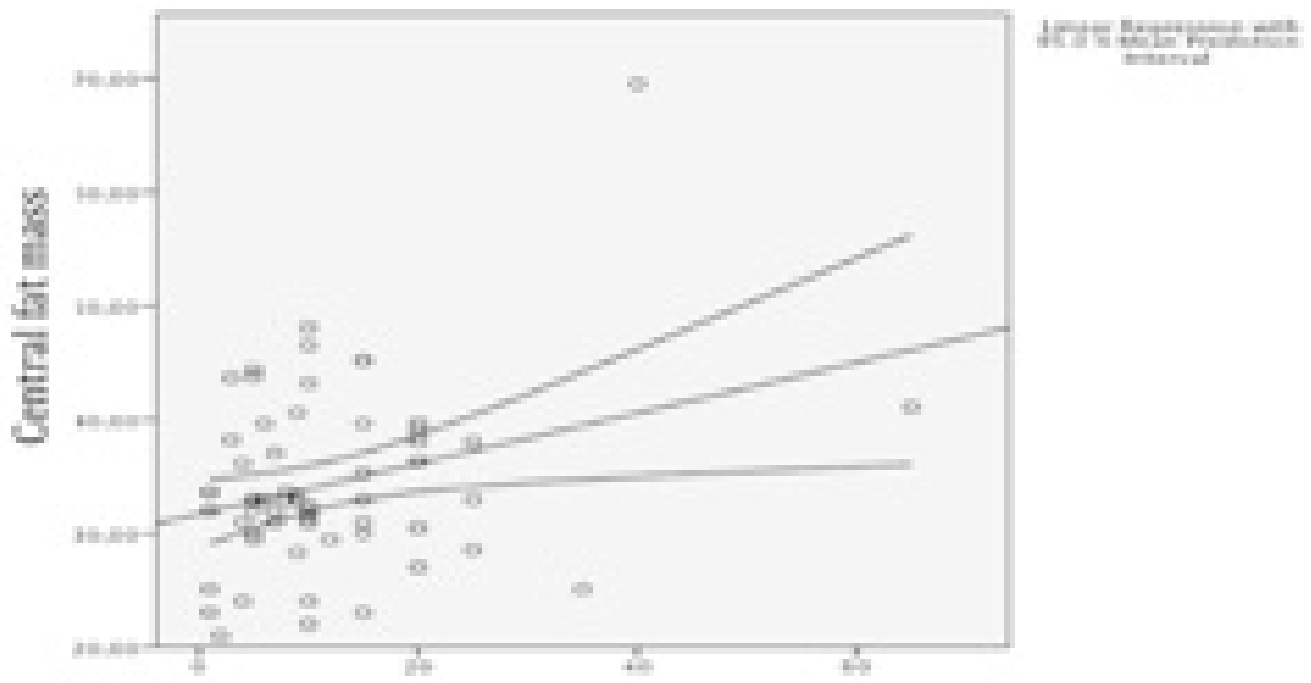

Tumor Burden

Figure 1. Central mass correlation with Tumor burden.

positive surgical margins in patients with localized disease. The authors observed how there was a non-significant trend to this association (OR:1.64 IC95:0.92-2.90). In our study, as in the case of Freeland, there was no association of parameters related to obesity (BMI or variables derived from the BEI) with the presence of positive surgical margins. Only two variables were associated with this fact, age and height. Probably, the greater number of surgeries with neurovascular bundle sparing in the group of younger patients (in order to preserve continence and potency) may have induced a higher percentage of positive surgical margins in these group of age. As height increases, patients use to have narrower pelvis with greater technical difficulties that, in many cases, could justify these positive margins (most of them iatrogenic margins during surgical manipulation or apical margins because of a worse view).
Neither Tomaszewski, et al. study [11] found an association between obesity (measured by BMI) and the presence of positive surgical margins $(\mathrm{p}=0,66)$. In the same way, Zilberman, et al. [12] retrospectively analysed 577 robotic radical prostatectomies and appreciated that there were no differences in rates of positive surgical margins depending on the BMI.

On the other hand, Campeggi, et al. [13] appreciated that obese patients had significantly a higher rate of positive surgical margins than non-obese patients. This group presented higher Gleason grade scores and more percentage of patients with non-organ-confined disease. This could be a confounding factor in establishing a relationship between obesity and positive surgical margins because there were more patients with higher Gleason grade and non-organ-confined disease between obese patients. 

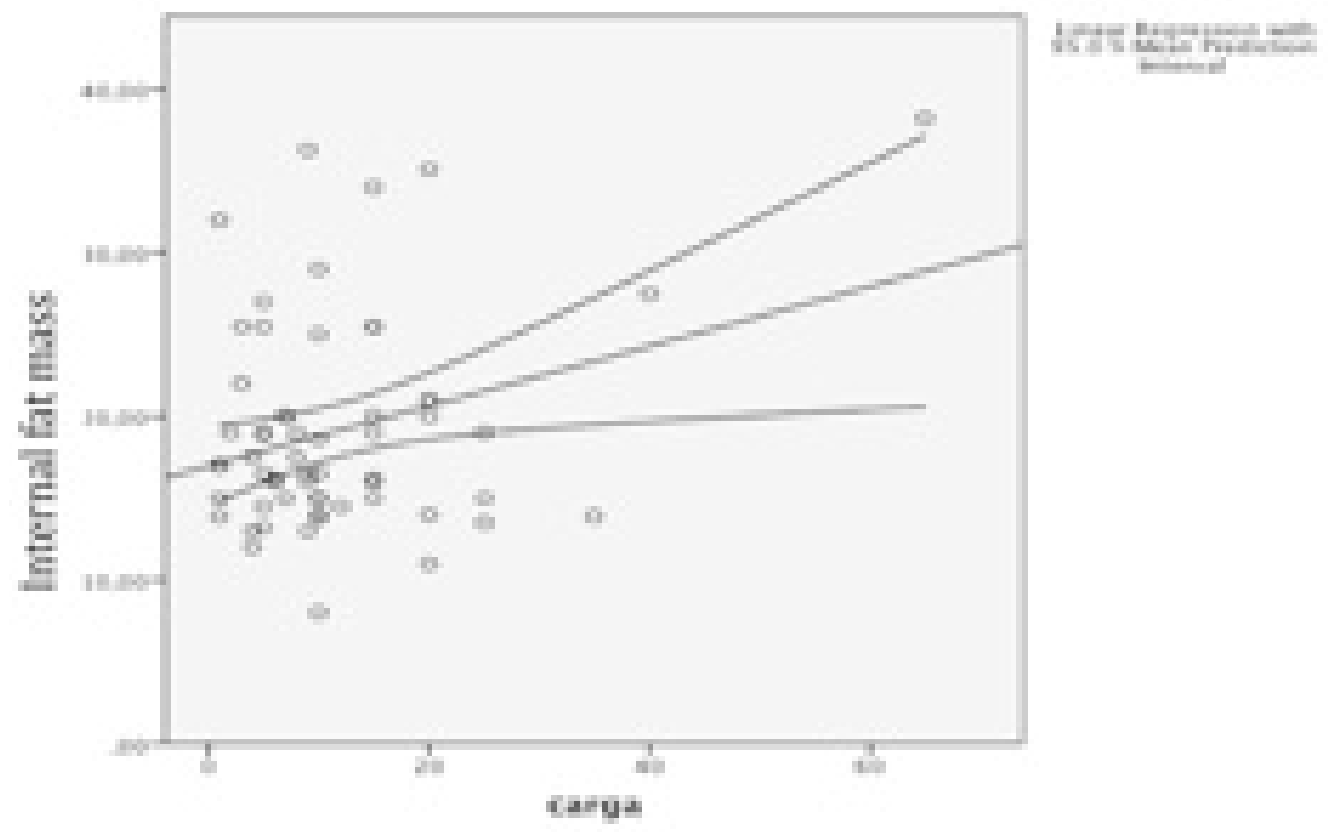

Figure 2. Correlation of internal fat mass.

The main limitation of this study is the sample size. This can be justified because this is a single centre study. Including more centres could increase the number of patients but may influence in some characteristics, as positive surgical margins, because of surgeons with less experience, altering our conclusions.

\section{Conclusions}

According to our results, we can conclude that BMI and internal body fat mass demonstrated an association with high Gleason grade in radical prostatectomy specimen. A weak positive correlation was showed between internal body fat mass and tumour burden. We found no association between these variables and positive surgical margins.

\section{Funding}

No funding has been received

\section{Conflict of Interest}

Authors declare no conflict of interest.

\section{Ethical approval}

All procedures performed in studies involving human participants were in accordance with the ethical standards of the institutional and/ or national research committee and with the 1964 Helsinki declaration and its later amendments or comparable ethical standards.

\section{Informed consent}

Informed consent was obtained from all individual participants included in the study.

\section{References}

1. Center MM, Jemal A, Lortet-Tieulent J, Ward E, Ferlay J, et al. (2012) International variation in prostate cancer incidence and mortality rates. Eur Urol 61: 1079-1092. [Crossref]

2. Sourbeer KN, Howard LE, Andriole GL, Moreira DM, Castro-Santamaria R, et al. (2015) Metabolic syndrome-like components and prostate cancer risk: results from the Reduction by Dutasteride of Prostate Cancer Events (REDUCE) study. BJU Int 115: 736-743. [Crossref]
3. Liao C, Gao W, Cao W (2015) Associations of Body Composition Measurements with Serum Lipid, Glucose and Insulin Profile: A Chinese Twin Study. PLoS One 10: $\mathrm{e} 0140595$.

4. Alves FD, Souza GC, Biolo A, Clausell N (2014) Comparison of two bioelectrical impedance devices and dual-energy X-ray absorciometry to evaluate body composition in heart failure. J Hum Nutr Diet 27: 632-638.

5. Stewart A, Marfell-Jones M, Olds T, de Ridder H (2011) International standards for anthropometric assessment. ISAK: Lower Hutt, New Zealand.

6. Amine EK, Baba NH, Belhadj M (2002) WHO: World Health Organization, Ginebra.

7. Epstein JI, Zelefsky MJ, Sjoberg DD, Nelson JB, Egevad L, et al. (2016) A contemporary prostate cancer grading system: A validated alternative to the Gleason score. Eur Urol 69: 428-435.

8. Freedland SJ, Aronson WJ, Kane CJ, Presti JC Jr, Amling CL, et al. (2004) Impact of obesity on biochemical control alter radical prostatectomy for clinically localized prostate cancer: a report by the Shared Equal Access Regional Cancer Hospital database study group. J Clin Oncol 22: 446-453.

9. Freedland SJ, Bañez LL, Sun LL, Fitzsimons NJ, Moul JW (2009) Obese men have higher grade and larger tumours: an analysis of the duke prostate center database Prostate Cancer Prostatic Dis 12: 259-263.

10. Amling CL, Kane CJ, Riffenburgh RH, Ward JF, Roberts JL, et al. (2001) Relationship between obesity and race in predicting adverse pathologic variables in patients undergoing radical prostatectomy. Urology 58: 723-728.

11. Tomaszewski JJ, Chen YF, Bertolet M, Ristau BT, Woldemichael E, et al. (2013) Obesity is not associated with aggressive pathologic features or biochemical recurrence alters radical prostatectomy. Urology 81: 992-996.

12. Zilberman DE, Tsivian M, Yong D, Ferrandino MN, Albala DM (2012) Does body mass index have an impact on the rate and location of positive surgical margins following robot assisted radical prostatectomy. Urol Oncol 30: 790-793.

13. Campeggi A, Xylinas E, Ploussard G, Ouzaid I, Fabre A, et al. (2012) Impact of body mass index on perioperative morbidity, oncological, and functional outcomes alter extraperitoneal laparoscopic radical prostatectomy. Urology 80: 576-584.

Copyright: (C2017 Morán E. This is an open-access article distributed under the terms of the Creative Commons Attribution License, which permits unrestricted use, distribution, and reproduction in any medium, provided the original author and source are credited. 